\title{
Glioblastoma treatment: Where to now?
}

\author{
Thomas MB Ware and Hong-Jian Zhu* \\ Department of Surgery (RMH), University of Melbourne, Parkville, Australia
}

\begin{abstract}
Glioblastoma (GBM) remains an incurable disease with a poor overall survival. Despite extensive research into clinical trials, temozolomide remains the only therapeutic agent to improve patient survival in the past 50 years. This is despite only providing a modest increase of 2.5 months to median survival. Resistance to traditional therapies has become a hallmark of GBM, owing to its complex and undetermined molecular landscape. Studies now suggest that GBM is a disease of genetic subtypes and require tailored approaches to therapeutic care. Further strategies for GBM treatment involve targeting tumour associated neovascularisation. While early attempts to attenuate the tumour vascularisation with anti-VEGF has not been successful, studies are now looking towards other angiogenic factors and novel mechanisms of neovascularisation that have yet to be explored. A shift towards understanding the molecular and biological mechanisms of GBM pathogenesis represents a promising new strategy for treatment. Here we highlight some of the major developments to genetic profiling and anti-neovascularisation therapy.
\end{abstract}

\section{Introduction}

Glioblastoma (GBM) is the most common glioma and one of the most debilitating human cancers [1,2]. Although relatively uncommon, GBM is associated with a disproportionate morbidity and mortality in the population with a median survival of 12-15 months owing to inevitable tumour recurrence [3]. Clinically, most patients present with de novo primary GBM ( 90\%), with few patients progressing from a lower grade glioma to secondary GBM $[4,5]$. Histopathological examination of primary and secondary GBM are largely indistinguishable, though secondary GBM is typically diagnosed at a younger age and associates with a more favourable prognosis. The distinction between the clinical presentations is primarily due to distinct molecular signatures that are thought to govern tumourigenesis of each subtype [6]. Despite these clinical and molecular differences, all patients are treated with the same aggressive standard of care consisting of maximal resection, concurrent chemoradiation and adjuvant temozolomide-based chemotherapy for newly diagnosed GBM [7]. $O^{6}$-methylguanine-DNA methyltransferase (MGMT) status is routinely performed to assess a patient's response to temozolomide, with minimal to no benefit derived in patients who lack this methylation [8]. Although younger patients and secondary GBM cases respond markedly better to the standard of care, treatment response is largely dependent on the genetic landscape of the tumour $[8,9]$.

\section{Reassessing approaches to Glioblastoma therapy research}

With over a century of GBM research conducted, there have been few advances in GBM treatment. Recent improvements in surgical techniques and neuroimaging modalities have improved tumour care and treatment decision making but have provided minimal impact on patient survival [10]. Even the chemotherapy agent temozolomide, which is commonly regarded as the most significant breakthrough of the past 50 years, has provided a minor median survival improvement of 2.5 months with an optimal standard of care [3]. In real-world clinical situations, most patients do not receive the complete standard of care due to poor prognostic factors and concern of cytotoxicity of chemotherapy, particularly in elderly patients [11-13]. Alternate
FDA approved treatments are available for newly diagnosed GBM including the use of nitrosoureas, though the use of these agents remains controversial without an established standard of care. The lack of advancement for GBM therapy has led to extensive clinical trials to determine novel therapeutic approaches [14]. The results from these trials have not been encouraging, with temozolomide the only therapeutic agent showing clinical efficacy $[14,15]$. The low rate of discovery from clinical trials can be largely attributed to the complex biology of GBM, making it highly refractive to standard non-specific treatments [16]. There is a need to shift away from chemotherapy based clinical trials that do not address the underlying etiology of the disease and are commonly associated with high toxicity to the patients $[7,17]$. Recent discoveries of prognostic factors for patients, demonstrate the importance of GBM pathophysiology in treatment response $[6,18]$. The success of pursuing such approaches has been demonstrated with therapies targeting HER2-amplified breast cancers, Chronic myeloid leukaemia (CML) harbouring the $B C R-A B L$ translocation, $B R A F$ mutant melanoma among other cancer-specific tumour promotors [19]. By targeting pathways that promote GBM progression there is the potential to provide meaningful clinical responses without increasing the burden to the patient's quality of life.

\section{Genomic alterations define glioblastoma}

Early genome-wide profiling of GBM demonstrated a remarkable genomic heterogeneity within the tumour suggesting the existence of molecular subclasses that may clinically impact treatment $[20,21]$. The Cancer Genome Atlas (TCGA) group set out to extensively characterise the genomic landscape of GBM and identify the major cancer-causing genomic alterations $[22,23]$. The study identified major alterations to the Receptor Tyrosine Kinase (RTK)/RAS/PI3K pathway, in addition

${ }^{\star}$ Correspondence to: Hong-Jian Zhu, Department of Surgery (RMH \& WH), University of Melbourne, The Royal Melbourne Hospital, Parkville 3050, Australia, Tel: 6138344 3025, Fax: 6139347 6488, E-mail: hongjian@ unimelb.edu.au

Received: June 10, 2018; Accepted: June 25, 2018; Published: June 28, 2018 
to $\mathrm{p} 53$ and RB mutations. EGFR activating mutations or amplification was the most common alteration found to be expressed in $57.4 \%$ of GBM cases and has gained much interest as a primary driver of tumour proliferation and survival. Furthermore $50 \%$ of GBM tumours with a EGFR amplification, harbor a EGFR variant (EGFRvIII) with in frame deletion of exons2-7 resulting in constitutive activation and enhanced RAS/PI3K signaling [24-26]. Mutations in PI3K (25.1\%) and deletions/ mutations in PTEN (41\%) were also commonly found and reported to be mutually exclusive with $59.4 \%$ of GBM presenting with one or the other [22]. These genomic alterations reaffirm a strong association between RTK/RAS/PI3K pathways and tumourigenesis.

The TCGA research network also identified mutations in the p53 pathway, namely amplification of $M D M 1 / 2 / 4(15.1 \%)$ and homozygous deletion or inactivating mutations in TP53 (27.9\%) [22]. In the RB signalling pathway homozygous deletion or inactivating mutations were found in $C D K N 2 A / C D K N 2 B(61 \%), R B 1(7.6 \%)$ and amplification of $C D K 4 / 6(15.5 \%)$. Overall signalling alterations were found in RTK/ RAS/PI3K signalling in $90 \%$ cases, p53 pathways in $86 \%$ cases and RB signalling in $79 \%$ suggesting a common genetic component to most GBM tumours.

The identification of IDH mutations in GBM provided differentiation between what had until then been only identified as histopathological primary and secondary GBM [6,27]. IDH1 mutations were identified in over $80 \%$ of grade II and III gliomas and were conserved during transformation to secondary GBM [5]. In contrast IDH mutations in primary GBM are rare occurring in under $5 \%$ of cases, most associated with younger age and genetic profiles more similar to secondary GBM. IDH mutations are thought to be an early initiator of tumourigenesis and progression to secondary GBM requires further genomic alterations [4]. The majority of secondary GBM cases have IDH1 and TP53 mutations, whereas primary GBM is most commonly associated with EGFR amplification and loss of PTEN function. This molecular characterization has been further expanded to four GBM subtypes Proneural, Neural, Classical and Mesenchymal each with its own specific differentiation lineage and prognostic outcome $[6,21]$. While these findings present a unique opportunity for individualised subtype-specific therapy, recent studies have reported a proneural-mesenchymal shift following irradiation, contributing to radioresistance [28-30]. The inherent plasticity in GBM discerns the need for individualised treatment and highlights some of the limitations in current clinical trial developments. Through identification of treatment-induced genetic alterations patients may receive adaptive and specific tailored-therapy with improved clinical outcomes [18].

The identification of multiple genetic signature pathways to GBM tumourigenesis underscore the complexity of the disease and obstacles to treatment. While current diagnosis and treatment is standard regardless of molecular subtype, successful development of new therapeutic targets will need to account for the intrinsic cellular differences regulating GBM behaviour.

\section{Exploring neovascularisation as a therapeutic target}

GBM tumours are among the most highly vascularised of all solid malignancies and are distinguished from lower grade tumours by necrosis and microvascular hyperplasia [31-33]. This histopathological classification is independent of tumour cell morphology and carries an inordinate degree of prognostic power suggesting that they mechanistically linked to tumour progression [34,35]. Tumours require adequate blood supply for growth and survival, therefore neovascularisation presents as promising therapeutic targets [36]. Targeting abnormally activated tumour vasculature has the additional benefit of overcoming many problems associated with chemotherapy such as tumour resistance, high levels of cytotoxicity and lack of efficient distribution [37]. Therefore, there has been much interest into the study of angiogenesis which is thought to be a key mediator of microvascular hyperplasia in all forms of vascular cancers [38].

The success of antiangiogenic therapy for metastatic colorectal cancer, accelerated the FDA approval of Bevacizumab (Avastin ${ }^{\oplus}$ ) in 2009 for use in GBM following an uncontrolled phase II GBM clinical trial [39]. Bevacizumab is a monoclonal antibody targeting angiogenesis through inhibition of VEGF ligand. While there are many signalling pathways involved in angiogenesis, VEGF, has been the most extensively studied and has been reported in plasma and tumour samples obtained from GBM patients, where its overexpression correlated with poorer prognosis [40,41]. Despite the early promise that bevacizumab would revolutionise GBM treatment, all clinical trials have failed to improve overall survival for both newly diagnosed and recurrent GBM $[14,42]$. The reasons for this lack of efficacy remain controversial yet no study has shown a specificity of bevacizumab for tumour-associated vascularisation. More recent clinical trials have investigated the efficacy of VEGF traps, VEGFR kinase inhibitors and monoclonal antibodies for recurrent GBM [43]. These clinical trials have also been disappointing as single or concomitant agents producing no improvement to overall survival. The dismal progress of these antiangiogenic inhibitors strongly suggests that there are alternate pathways to tumour induced-neovascularisation in GBM that requires a more comprehensive understanding of the underlying mechanisms.

FGF-2 is another important contributor to angiogenesis by promoting proliferation and migration of endothelial cells [44]. While its role in early vascular development remains controversial, in vivo GBM studies with dominant-negative FGFR2 or FGFR1 inhibited glioma C6 tumour development in rats and decreased microvessel density [45]. A novel inhibitor 2,5DHPS targeting FGF was also found to strongly inhibit GBM invasion and suppress associated angiogenesis in a C6 orthotopic glioma rat model [46]. These early studies suggest a potential mechanism of FGF-2 in GBM vascularisation.

Among the other well characterized angiogenesis cytokines, TGF- $\beta$ signalling has been shown to have a key role in microvascular modulation and is amplified in GBM tumours conferring to poorer prognosis $[47,48]$. Genetic mutations to the TGF- $\beta$ type I receptor ALK1 and its accessory receptor endoglin cause the vascular condition hereditary hemorrhagic telangiectasia (HTT) in humans that is characterized by arteriovenous malformations in organs [49]. Endothelial cell specific deletion of ALK1 and endoglin in vivo completely recapitulate the vascular abnormalities seen in HHT underscoring the importance of TGF- $\beta$ signalling in vascular development [50-52]. Loss of ID1, downstream of TGF- $\beta /$ ALK1 signaling in GBM tumour endothelial cells, results in downregulation of several key proangiogenic genes, providing the potential for multiple angiogenic pathways [53]. In the GBM microenvironment endoglin has been identified as a sensitive marker of angiogenic blood vessel formation and associates with poorer patient survival [54,55]. Current studies suggest an important role for TGF- $\beta$ /ALK1 signalling in tumour angiogenesis and further study of its role in GBM pathobiology is needed to harness its potential [56].

Despite the interest of angiogenic inhibitors over the last decade for the treatment of GBM, few studies have fully examined the contribution of angiogenesis-independent pathways to neovascularisation. Vascular 
co-option and de novo vasculogenesis have both been reported in GBM [57,58]. Possible molecular links between hypoxic and angiopoietin pathways are suspected to mediate GBM vascular co-option and have been previously described as an initial step to GBM vascularisation [59]. Differentiation of circulating bone marrow-derived cells (BMDCs) has also been identified to contribute to vasculogenesis of GBM. In Id1 mutant mice angiogenic defects were observed to inhibit the growth of $\mathrm{PTEN}^{+/-}$tumour xenografts [53]. This phenotype was partially rescued by BMDCs. Other studies, however, have shown only a minor contribution of BMDC to GBM vasculature following VEGF inhibition [60]. It is yet to be determined whether BMDCs represent a novel target for GBM therapy.

A recently identified mechanism of glioma vascularisation involves the formation of perfusable vessel-like networks by tumour cells [61]. These structures are completely devoid of endothelial cells and have been termed vasculogenic mimicry (VM), following their ability to create pseudo de novo vascular channels [62]. Histologically VM structures are confirmed by $\mathrm{PAS}^{+} \mathrm{CD} 31 / \mathrm{CD} 34$ vascular patterns. Further molecular characterization of these tumour cells demonstrate expression of endothelial cell associated genes that recapitulated the embryonic development of vasculogenesis $[62,63]$. These observations led to the four defining characteristics of VM: 1) patterned vascular channels of aggressive and primary tumours are different from endothelial-derived angiogenic vessels; 2) highly invasive tumour cells but not poorly invasive ones have the intrinsic ability to form patterned vascular channels in absence of endothelium; 3) Tumour cells that generate these patterns are highly plastic and aberrantly express genes associated with embryonic stem cells; and 4) the generation of these patterned vascular channels is a novel pathway to generate microcirculation. While these structures have been identified in GBM patient samples and are associated with poorer prognosis, the mechanisms involved in the formation of these structures remains unclear $[64,65]$.

Even more recently GBM stem cells have been observed to transdifferentiate into an endothelial cell phenotype [66-69]. While these structures have been found to form separate vascular channels, in contrast to VM these endothelial-like tumour cells can also integrate into existing endothelial cell lined blood vessels forming mosaic blood vessels $[67,68]$. The biological significance and mechanisms regulating this transdifferentiating behaviour are still unknown but may offer new explanation and opportunities for neovascularisation treatment.

GBM-induced neovascularisation is undoubtedly more complex than early VEGF therapies anticipated. It is possible that multiple signalling pathways are involved within angiogenesis and new strategies for multiple targeting of angiogenic pathways are needed. Additionally, further research is needed to understand the contribution of angiogenesis-independent pathways to neovascularisation. By improving our understanding of basic GBM vascular pathology we may still realize the potential of neovascularisation inhibitors.

\section{Conclusions}

Previous approaches to advancing GBM treatment through non-specific treatments have been unsuccessful providing marginal improvements to patient outcome in over 50 years. It is clear that a new avenue of therapeutic exploration is needed that addresses the key mechanisms governing GBM pathogenesis. The information achieved from these molecular genetic and biological studies will develop and improve the next generation of clinical trials and therapeutic development.

\section{References}

1. Ostrom QT, Gittleman H, Liao P, Vecchione-Koval T, Wolinsky Y, et al. (2017) CBTRUS Statistical Report: Primary brain and other central nervous system tumors diagnosed in the United States in 2010-2014. Neuro Oncol 19: v1-v88. [Crossref]

2. Wen PY, Kesari S (2008) Malignant gliomas in adults. $N$ Engl J Med 359: 492-507. [Crossref]

3. Stupp R, Mason WP, van den Bent MJ, Weller M, Fisher B, et al. (2005) Radiotherapy plus concomitant and adjuvant temozolomide for glioblastoma. $N$ Engl J Med 352: 987 996. [Crossref]

4. Nobusawa S, Watanabe T, Kleihues P, Ohgaki H (2009) IDH1 mutations as molecular signature and predictive factor of secondary glioblastomas. Clin Cancer Res 15: 60026007. [Crossref]

5. Yan H, Parsons DW, Jin G, McLendon R, Rasheed BA, et al. (2009) IDH1 and IDH2 mutations in gliomas. $N$ Engl J Med 360: 765-773. [Crossref]

6. Verhaak RG, Hoadley KA, Purdom E, Wang V, Qi Y, et al. (2010) Integrated genomic analysis identifies clinically relevant subtypes of glioblastoma characterized by abnormalities in PDGFRA, IDH1, EGFR, and NF1. Cancer Cell 17: 98-110. [Crossref]

7. Stupp R, Hegi ME, Mason WP, van den Bent MJ, Taphoorn MJ, et al. (2009) Effects of radiotherapy with concomitant and adjuvant temozolomide versus radiotherapy alone on survival in glioblastoma in a randomised phase III study: 5-year analysis of the EORTC-NCIC trial. Lancet Oncol 10: 459-66. [Crossref]

8. Hegi ME, Diserens AC, Gorlia T, Hamou MF, de Tribolet N, et al. (2005) MGMT gene silencing and benefit from temozolomide in glioblastoma. $N$ Engl J Med 352 997-1003. [Crossref]

9. Qazi MA, Vora P, Venugopal C, Sidhu SS, Moffat J, et al. (2017) Intratumora heterogeneity: pathways to treatment resistance and relapse in human glioblastoma. Ann Oncol 28: 1448-1456. [Crossref]

10. deSouza RM, Shaweis H, Han C, Sivasubramaniam V, Brazil L, et al. (2016) Has the survival of patients with glioblastoma changed over the years? Br J Cancer 114: 146 150. [Crossref]

11. Holdhoff, M, Chamberlain MC (2013) Controversies in the treatment of elderly patients with newly diagnosed glioblastoma. J Natl Compr Canc Netw 11: 1165-1172. [Crossref]

12. Keime-Guibert F, Chinot O, Taillandier L, Cartalat-Carel S, Frenay M, et al. (2007) Radiotherapy for glioblastoma in the elderly. N Engl J Med 356: 1527-1535. [Crossref]

13. Tully PA, Gogos AJ, Love C, Liew D, Drummond KJ, et al. (2016) Reoperation for Recurrent Glioblastoma and Its Association With Survival Benefit. Neurosurgery 79: 678-689. [Crossref]

14. Cihoric N, Tsikkinis A, Minniti G, Lagerwaard FJ, Herrlinger U, et al. (2017) Current status and perspectives of interventional clinical trials for glioblastoma - analysis of ClinicalTrials.gov. Radiat Oncol 12: 1. [Crossref]

15. Yin AA, Cheng JX, Zhang X, Liu BL (2013) The treatment of glioblastomas: a systematic update on clinical Phase III trials. Crit Rev Oncol Hematol 87: 265-282. [Crossref]

16. Osuka S, Van Meir EG (2017) Overcoming therapeutic resistance in glioblastoma: the way forward. J Clin Invest 127: 415-426. [Crossref]

17. Weiss RB, Issell BF (1982) The nitrosoureas: carmustine (BCNU) and lomustine (CCNU). Cancer Treat Rev 9: 313-330. [Crossref]

18. Nguyen HS, Shabani S, Awad AJ, Kaushal M, Doan N (2018) Molecular Markers of Therapy-Resistant Glioblastoma and Potential Strategy to Combat Resistance. Int $J$ Mol Sci 19: 1765. [Crossref]

19. Torti D, Trusolino L (2011) Oncogene addiction as a foundational rationale for targeted anti-cancer therapy: promises and perils. EMBO Mol Med 3: 623-636. [Crossref]

20. Liang, Diehn M, Watson N, Bollen AW, Aldape KD, et al., (2005) Gene expression profiling reveals molecularly and clinically distinct subtypes of glioblastoma multiforme. Proc Natl Acad Sci U S A 102: 5814-5819. [Crossref]

21. Phillips HS, Kharbanda S, Chen R, Forrest WF, Soriano RH, et al. (2006) Molecula subclasses of high-grade glioma predict prognosis, delineate a pattern of disease progression, and resemble stages in neurogenesis. Cancer Cell 9: 157-173. [Crossref]

22. Brennan CW, Verhaak RG, McKenna A, Campos B, Noushmehr H, et al. (2013) The somatic genomic landscape of glioblastoma. Cell 155: 462-477. [Crossref]

23. Cancer Genome Atlas Research (2008) Comprehensive genomic characterization defines human glioblastoma genes and core pathways. Nature 455: 1061-1068. [Crossref]

24. Del Vecchio CA, Giacomini CP, Vogel H, Jensen KC, Florio T, et al. (2013) EGFRvIII gene rearrangement is an early event in glioblastoma tumorigenesis and expression defines a hierarchy modulated by epigenetic mechanisms. Oncogene 32: 2670-2681. [Crossref] 
25. Luwor RB, Zhu HJ, Walker F, Vitali AA, Perera RM, et al. (2004) The tumorspecific de2-7 epidermal growth factor receptor (EGFR) promotes cells survival and heterodimerizes with the wild-type EGFR. Oncogene 23: 6095-6104. [Crossref]

26. Nishikawa R, Ji XD, Harmon RC, Lazar CS, Gill GN, et al. (1994) A mutant epidermal growth factor receptor common in human glioma confers enhanced tumorigenicity. Proc Natl Acad Sci U S A 91: 7727-7731. [Crossref]

27. Parsons DW, Jones S, Zhang X, Lin JC, Leary RJ, et al. (2008) An integrated genomic analysis of human glioblastoma multiforme. Science 321: 1807-1812. [Crossref]

28. Bhat KPL, Balasubramaniyan V, Vaillant B, Ezhilarasan R, Hummelink K, et al., (2013) Mesenchymal differentiation mediated by NF-kappaB promotes radiation resistance in glioblastoma. Cancer Cell 24: 331-346. [Crossref]

29. Halliday J, Helmy K, Pattwell SS, Pitter KL, LaPlant Q, et al. (2014) In vivo radiation response of proneural glioma characterized by protective $\mathrm{p} 53$ transcriptional program and proneural-mesenchymal shift. Proc Natl Acad Sci U S A 111: 5248-5253. [Crossref]

30. Ma H, Rao L, Wang HL, Mao ZW, Lei RH, et al. (2013) Transcriptome analysis of glioma cells for the dynamic response to gamma-irradiation and dual regulation of apoptosis genes: a new insight into radiotherapy for glioblastomas. Cell Death Dis 4: e895. [Crossref]

31. Batchelor TT, Reardon DA, de Groot JF, Wick W, Weller M (2014) Antiangiogenic therapy for glioblastoma: current status and future prospects. Clin Cancer Res 20: 5612-5619. [Crossref]

32. Brat DJ, Castellano-Sanchez A, Kaur B, Van Meir EG (2002) Genetic and biologic progression in astrocytomas and their relation to angiogenic dysregulation. Adv Anat Pathol 9: 24-36. [Crossref]

33. Rong Y, Durden DL, Van Meir EG, Brat DJ (2006) 'Pseudopalisading' necrosis in glioblastoma: a familiar morphologic feature that links vascular pathology, hypoxia, and angiogenesis. J Neuropathol Exp Neurol 65: 529-539. [Crossref]

34. Burger PC, Green SB (1987) Patient age, histologic features, and length of survival in patients with glioblastoma multiforme. Cancer 59: 1617-1625.

35. Raza SM, Lang FF, Aggarwal BB, Fuller GN, Wildrick DM, et al. (2002) Necrosis and glioblastoma: a friend or a foe? A review and a hypothesis. Neurosurgery 51: 2-12. [Crossref]

36. Folkman J (2007) Angiogenesis: an organizing principle for drug discovery? Nat Rev Drug Discov 6: 273-286. [Crossref]

37. Drean A, Goldwirt L, Verreault M, Canney M, Schmitt C, et al. (2016) Blood-brain barrier, cytotoxic chemotherapies and glioblastoma. Expert Rev Neurother 16: 12851300. [Crossref]

38. Nishida N, Yano H, Nishida T, Kamura T, Kojiro M (2006) Angiogenesis in cancer. Vasc Health Risk Manag 2: 213-219. [Crossref]

39. Vredenburgh JJ, Desjardins A, Herndon JE 2nd, Dowell JM, Reardon DA, et al. (2007) Phase II trial of bevacizumab and irinotecan in recurrent malignant glioma. Clin Cancer Res 13: 1253-1259. [Crossref]

40. Ferrara N (2002) VEGF and the quest for tumour angiogenesis factors. Nat Rev Cancer 2: 795-803. [Crossref]

41. Plate KH, Risau W (1995) Angiogenesis in malignant gliomas. Glia 15: 339-347. [Crossref]

42. Reardon DA, Turner S, Peters KB, Desjardins A, Gururangan S, et al. (2011) A review of VEGF/VEGFR-targeted therapeutics for recurrent glioblastoma. J Natl Compr Canc Netw 9: 414-427. [Crossref]

43. Winkler F, Osswald M, Wick W (2018) Anti-Angiogenics: Their Role in the Treatment of Glioblastoma. Oncol Res Treat 41: 181-186. [Crossref]

44. Presta M, Dell'Era P, Mitola S, Moroni E, Ronca R, et al. (2005) Fibroblast growth factor/fibroblast growth factor receptor system in angiogenesis. Cytokine Growth Factor Rev 16: 159-178. [Crossref]

45. Auguste P, Gursel DB, Lemiere S, Reimers D, Cuevas P, et al. (2001) Inhibition of fibroblast growth factor/fibroblast growth factor receptor activity in glioma cells impedes tumor growth by both angiogenesis-dependent and -independent mechanisms. Cancer Res 61: 1717-1726.

46. Cuevas P, Carceller F, Angulo J, González-Corrochano R, Cuevas-Bourdier A, et al. (2011) Antiglioma effects of a new, low molecular mass, inhibitor of fibroblast growth factor. Neurosci Lett 491: 1-7. [Crossref]

47. Goumans MJ, Liu Z, ten Dijke P (2009) TGF-beta signaling in vascular biology and dysfunction. Cell Res 19: 116-127. [Crossref]
48. Joseph JV, Balasubramaniyan V, Walenkamp A, Kruyt FA (2013) TGF- $\beta$ as a therapeutic target in high grade gliomas - promises and challenges. Biochem Pharmacol 85: 478485. [Crossref]

49. Johnson DW, Berg JN, Baldwin MA, Gallione CJ, Marondel I, et al. (1996) Mutations in the activin receptor-like kinase 1 gene in hereditary haemorrhagic telangiectasia type 2. Nat Genet 13: 189-195. [Crossref]

50. Arthur HM, Ure J, Smith AJ, Renforth G, Wilson DI, et al. (2000) Endoglin, an ancillary TGFbeta receptor, is required for extraembryonic angiogenesis and plays a key role in heart development. Dev Biol 217: 42-53. [Crossref]

51. Lebrin F, Goumans MJ, Jonker L, Carvalho RL, Valdimarsdottir G, et al. (2004) Endoglin promotes endothelial cell proliferation and TGF-beta/ALK1 signal transduction. EMBO J 23: 4018-4028. [Crossref]

52. Park SO, Lee YJ, Seki T, Hong KH, Fliess N, et al. (2008) ALK5- and TGFBR2independent role of ALK1 in the pathogenesis of hereditary hemorrhagic telangiectasia type 2. Blood 111: 633-642. [Crossref]

53. Ruzinova MB, Schoer RA, Gerald W, Egan JE, Pandolfi PP, et al. (2003) Effect of angiogenesis inhibition by Id loss and the contribution of bone-marrow-derived endothelial cells in spontaneous murine tumors. Cancer Cell 4: 277-289. [Crossref]

54. Rosen LS, Gordon MS, Robert F, Matei DE (2014) Endoglin for targeted cancer treatment. Curr Oncol Rep 16: 365. [Crossref]

55. Tian H, Huang JJ, Golzio C, Gao X, Hector-Greene M, et al. (2018) Endoglin interacts with VEGFR2 to promote angiogenesis. FASEB J 32: 2934-2949. [Crossref]

56. Luwor RB, Kaye AH, Zhu HJ (2008) Transforming growth factor-beta (TGF-beta) and brain tumours. J Clin Neurosci 15: 845-855. [Crossref]

57. Holash J, Maisonpierre PC, Compton D, Boland P, Alexander CR, et al. (1999) Vessel cooption, regression, and growth in tumors mediated by angiopoietins and VEGF. Science 284: 1994-1998. [Crossref]

58. Folkins C, Shaked Y, Man S, Tang T, Lee CR, et al. (2009) Glioma tumor stem-like cells promote tumor angiogenesis and vasculogenesis via vascular endothelial growth factor and stromal-derived factor 1. Cancer Res 69: 7243-7251. [Crossref]

59. Zagzag D, Amirnovin R, Greco MA, Yee H, Holash J, et al. (2000) Vascular apoptosis and involution in gliomas precede neovascularization: a novel concept for glioma growth and angiogenesis. Lab Invest 80: 837-849. [Crossref]

60. Machein MR, Renninger S, de Lima-Hahn E, Plate KH (2003) Minor contribution of bone marrow-derived endothelial progenitors to the vascularization of murine gliomas. Brain Pathol 13: 582-597. [Crossref]

61. Maniotis AJ, Folberg R, Hess A, Seftor EA, Gardner LM, et al. (1999) Vascular channel formation by human melanoma cells in vivo and in vitro: vasculogenic mimicry. $A m J$ Pathol 155: 739-752. [Crossref]

62. Folberg R, Maniotis AJ (2004) Vasculogenic mimicry. APMIS 112: 508-525. [Crossref]

63. Folberg R, Hendrix MJ, Maniotis AJ (2000) Vasculogenic mimicry and tumor angiogenesis. Am J Pathol 156: 361-381. [Crossref]

64. Niclou SP, Danzeisen C, Eikesdal HP, Wiig H, Brons NH, et al. (2008) A novel eGFPexpressing immunodeficient mouse model to study tumor-host interactions. FASEB $J$ 22: 3120-3128. [Crossref]

65. Yue WY, Chen ZP (2005) Does vasculogenic mimicry exist in astrocytoma? J Histochem Cytochem 53: 997-1002. [Crossref]

66. Scully S, Francescone R, Faibish M, Bentley B, Taylor SL, et al. (2012) Transdifferentiation of glioblastoma stem-like cells into mural cells drives vasculogenic mimicry in glioblastomas. J Neurosci 32: 12950-12960. [Crossref]

67. Ricci-Vitiani L, Pallini R, Biffoni M, Todaro M, Invernici G, et al. (2010) Tumour vascularization via endothelial differentiation of glioblastoma stem-like cells. Nature 468: 824-828. [Crossref]

68. Soda Y, Marumoto T, Friedmann-Morvinski D, Soda M, Liu F, et al. (2011) Transdifferentiation of glioblastoma cells into vascular endothelial cells. Proc Natl Acad Sci U S A 108: 4274-4280. [Crossref]

69. Wang R, Chadalavada K, Wilshire J, Kowalik U, Hovinga KE, et al. (2010) Glioblastoma stem-like cells give rise to tumour endothelium. Nature 468: 829-833. [Crossref]

Copyright: (C2018 Ware TMB. This is an open-access article distributed under the terms of the Creative Commons Attribution License, which permits unrestricted use, distribution, and reproduction in any medium, provided the original author and source are credited. 